\title{
Vorwort und Danksagung
}

Vorliegende Studie ist die überarbeitete Version meiner Habilitationsschrift «Gestaltphonologische Interpretation der komplex-vokalischen Wortgestaltung im Portugiesischen, Spanischen, Französischen, Italienischen und Rumänischen», die 2016 vom Fakultätsrat der Fakultät für Sprach-, Literatur- und Kulturwissenschaften der Universität Regensburg einstimmig angenommen wurde.

Besonderen Dank gebührt deshalb meinen Habilitationsmentoren, Frau Prof. Dr. Maria Selig (Universität Regensburg, Romanistik), Herrn Prof. Dr. Andreas Dufter (Ludwig-Maximilians-Universität München, Romanistik) und Herrn Prof. Dr. Johannes Helmbrecht (Universität Regensburg, Allgemeine und Vergleichende Sprachwissenschaft) und meinen Habilitationsgutachtern, Frau Prof. Dr. Maria Selig (Universität Regensburg, Romanistik), Frau Prof. Dr. Christine Mooshammer (Humboldt-Universität zu Berlin, Phonetik) und Herrn Prof. Dr. Roland Schmidt-Riese (Katholische Universität Eichstätt, Romanistik).

Das Thema formte sich im Kontext meiner universitären Lehrtätigkeit an der Universität Regensburg heraus, wo ich in Kursen zur älteren Sprachstufe Diphthongierungsprozesse weitschweifig besprach, während ich in meinen Phonetik- und Phonologiekursen - nicht selten noch am selben Tag vor derselben Hörerschaft - erklären musste, dass es etwa im Gegenwartsfranzösischen keine Diphthonge gäbe, oder versuchte, diphthongisch-hiatische Realisierungsschwankungen spanischer Vokalsequenzen normativ in den Griff zu bekommen. Hier danke ich Frau Apl. Prof. Dr. Annette Endruschat (Universität Regensburg, Romanistik), die mich darin bestärkte, diesen Phänomenen auf den Grund zu gehen. Frau Dr. Patricia Serbac (George-Emil-Palade-Universität Târgu Mureș) danke ich für die Vermittlung rumänischer Muttersprachler und für die Diskussion rumänischer Vokalsequenzierungen. Zu Dank verpflichtet bin ich allen Probanden, die an den Sprachexperimenten teilgenommen haben.

Den Herausgebern der Beihefte zur Zeitschrift für romanische Philologie und dem De Gruyter-Verlag danke ich für die Aufnahme ins Verlagsprogramm. Danken möchte ich den anonymen Gutachtern meines Manuskripts sowie Frau Christine Henschel für die Betreuung der Drucklegung. Mein Dank gilt auch der Geschwister Boehringer Ingelheim Stiftung für Geisteswissenschaften für die großzügige Gewährung eines Druckkostenzuschusses.

Nürnberg, im Oktober 2021 
